that the colours can never be absolutely pure, and that their order is absolutely invariable; and the first thing that one must expect in a picture painted by an artist of intelligence is that this order shall not be interrupted or travestied.

In 624 a very interesting question of perspective is raised. If we imagine a room with an atmosphere very thickly laden with dust, and imagine further this room to be illuminated by a window with an ordinary windowsash: if the sun shines into the room, the sashes will cast their shadows on to the dust-laden air. As the sun is $93,000,000$ of miles away, or thereabouts, the shadows of all the horizontal sashes and of all the vertical sashes will be parallel. If on the other hand, instead of letting the sun throw shadows of the sashes in this way, we imagine a strong light not far away from the window to do it, the shadows of the two series of sashes will be no longer parallel, they will diverge, and the nearer the light is to the window the more they will diverge. It is of course quite understood that in the room itself the parallel sshadows cast by the sun could not appear to be truly parallel, for the reason that one part of the shadow must be nearer the eye than the other, but we cannot help thinking that the difference between this condition and the one which holds when the source of light is close to us, has not been sufficiently taken into account by the artist, so that a sun 93 yards off instead of $93,000,000$ of miles would have been very much more likely to produce the effect shown in the picture.

\section{A REVIEW OF LIGHTHOUSE WORK AND ECONOMY IN THE UNITED KINGDOM DURING THE PAST FIFTY YEARS. ${ }^{1}$}

\section{III.}

THE growth of improvement in lighthouse towers, lanterns, and apparatus has been glanced at. The source of light, or lamps and their aliment, must now be considered. It is probable that the phari of antiquity were open wood fires of great size on the summit of high towers or headlands. "Ignes" and "flammis" are terms used by Pliny and others, and Statius compares the pharos to the moon, not to a star as a modern poet would rather do. Yet Lucan speaks of "lampada," and Pliny fears that the flames might be mistaken for a constellation. But in these times oil could hardly have been used, as no form of lamp known could be applied with success. For 2000 years the iiluminant was mainly wood or coal. The Cordouan, in 1610, was kindled with oak logs. Coal fires were burnt at Harwich in the end of the eighteenth century. The Lizard was a coal fire in 1812 . St. Bees ceased to be one only in 1822 . The Isle of May remained a coal light for $18 \mathrm{I}$ years. It is now the single specimen of the electric light in Scotland. Sperm oil was not used before 1730 , and then hut on a small scale until the burners of Argand in 1783 and the reflectors of Teulère in the same year changed the character of lighthouse illumination. The Eddystone in 1759 threw its first beams over the waters from ten pounds of tallow candles, for which, in I8I I, wax was substituted.

But in 1837 sperm oil was the general aliment for our catoptric lights. In that year the oxy-oil lamp was proposed by Mr. Gurney. The principle of this light, known as the Bude, was a stream of oxygen injected into an oil flame, and it has since been tried with gas flames. It was followed by the Drummond lime-light, and by ignited platinum wire and various pyrotechnic mixtures. The Bude and Drummond lights were tried by the Trinity House without successful result. In 1845 a Parliamentary inquiry on oils led to the choice of rape-seed as a substi-

\footnotetext{
I Continued from p. $18 \mathrm{r}$.
}

tute for spermaceti, and in I 860 vegetable oil was being used everywhere, with perhaps a little gas for small lights. The single lamp of the dioptric system was then in England and Ireland the "fountain," and in Scotland the mechanical or clockwork lamp, as used in France, both having four concentric wicks. It was with this lamp that Fresnel established his first light at the Tour de Cordouan in I822. So far as can be ascertained, the electric spark was first practically suggested for a lighthouse in 1852 or 1853 (Holmes), or in 1854 (Watson), as will be later referred to. In 1860 , Prof. G. B. Airy wrote to the Royal Commissioners on Lights :- "At present the great excellence of a lighthouse is, or may be, the optician's part. The great defect and waste is in the source of light." Coal gas had been introduced in 1837 at the inner pier light of Troon (Ayrshire), and in 1847 it was used in the Hartlepool Heugh dioptric sea-light. From $186 ;$ to 1867 , gas was proposed for lighthouses in Ireland, but not officially adopted. In the same period, mineral oil, which had become familiar to English people in domestic lighting, and had been used in French lighthouses in lamps of a single wick and apparatus not larger than the fourth order, was much discussed as a suitable illuminant for sea-lights. After a long course of official experiment and inquiry, the unreserved use of mineral oil was authorized for lighthouses on land, and the Flamborough Head was the first Trinity light to receive the new illuminant (1872). One name is here worthy of distinction. Capt. H. H. Doty may justly be regarded as the chief demonstrator of the "promise and potency" of mineral oil. He also constructed a burner with multiple wicks which produced steady and brilliant flames. This burner is not, however, novel in its elements or combinations, and other petroleum burners of equal and superior merit have since been introduced. It is not on the Doty burner itself that his reputation is best founded, but on his strenuous and intelligent advocacy of mineral oil, and on his practical application of it to a multiple burner. It is gratifying to know that his services have been for this reason recognized by grants of money from the Governments of England and France.

Since 1872 the use of petroleum has been more and more extended, and it is now a trusted and perfectly safe illuminant. Until recently the variety known as "Young's lighthouse oil "was exclusively adopted by the Trinity House, its flashing-point being not lower than $142^{\circ}$, its specific gravity $0.8 \mathrm{I}$. Later varieties of it have a flashing. point of $154^{\circ}$. This fluid does not rise to the level of the top of the burner, but is confined to a certain distance below, whence the cotton wicks are charged with it by capillarity, and it is the vapour or gas that is ignited. The absence of overflow leaves the tips of the burner dry and unrefreshed, and therefore subject more or less to rapid deterioration. But in the heavy mineral oil lately recommended by the Trinity House, the specific gravity is between 0.828 and 0.832 (at $60^{\circ} \mathrm{F}$.), and the flashingpoint is not lower than $250^{\circ}$. This oil, therefore, may probably be allowed to overflow the burner like colza. There is also a very useful variety, under the name of "mineral sperm," which was first introduced by the writer into harbour and ships' signal lights. The flashingpoint has reached $270^{\circ}$.

The saving of expense in using mineral oil in a lighthouse may be understood thus. A six-wick burner of the best Trinity type consumes, when at full power, $79^{\circ} 4$ fluid ounces, or half a gallon hourly. In a year of about 4000 hours this would cost perhaps $£ 70$. Vegetable oil in the same quantity would cost perhaps $£ 250$. There would be no appreciable difference in intensity of light, but much in favour of mineral oil in the facility of service and in the smaller consumption of wicks. Pari passu with the adoption of this illuminant has been the improvement in the pressure and pump lamps and their burners effected by the Trinity House and by Messrs. 
Chance. It is, above all, to Sir James Douglass that credit is due in this field. For at least eighteen years he has worked unweariedly, and in the interest of the public service alone, at the perfecting of the burners which bear his name, whether for colza, paraffin, or gas ; and some striking developments have been attained by him. For instance, the typical four-wick vegetable-oil burner of Fresnel had an intensity of 230 candle-units, or $23^{\circ} 6$ units per square inch of sectional area. The Trinity four-wick has an intensity of $4 \mathrm{I} 5$ candle-units, or $44^{\circ} 3$ per square inch. The Trinity six-wick, perhaps the most serviceable and complete burner ever constructed, equals 730 candles, or 40.I per square inch. The Trinity seven-wick equals I 100 candles, or 46.9 per square inch, and the Trinity nine-wick equals 1785 candles, or $49^{\circ} 8$ per square inch. These burners are all for vegetable or mineral oil. The Trinity six-ring gas-burner equals 853 candles, or $44^{\circ} 4$ per square inch; and, which appears to be the most powerful combination ever attained, the Trinity ten-ring gas-burner reaches 2619 candles, or $50^{\circ} 9$ per square inch of sectional area. The admirable expanding gas-burners of Mr. Wigham are hardly less powerful. They are formed of concentric circles of jets from 28 to 108 in number, disposed so as to suit optical apparatus of several degrees of size, and weather of every degree of clearness. To this gentleman must be accorded the same pre-eminence in the skilful use of gas for lighthouses as to Capt. Doty for the skilful use of mineral oil. His ingenious combinations and contrivances, not only in regard to power, but to distinctiveness of character, are seen to great advantage in Galley Head and other notable Irish lights. It has been urged against gas flames of the largest dimensions on this system, that a portion of light escapes lenticular action, yet this very ex-focality has been found to have a useful side, for it tends to produce a glare or glow in the heavens, visible to mariners when the tower is beneath the horizon, and, in some circumstances, positively useful to them. (The electric light produces a similar effect, though in a different manner.) A more serious objection to large gas flames, especially when used in triform or quadriform series, appears to be the excessive heat, which is capable of injuring the delicate optical glass, and is hardly favourable to the keepers. It is probable that the hyper-radial apparatus just introduced may, both as relates to condensation of light and to mitigation of heat, be well suited to gas-burners of these striking magnitudes. Of the thirty-two dioptric sea-lights in Ireland, about one-fourth are successfully endowed with the gas-illuminant. Of the sixty-five in England, the Haisboro' is the only case. There is no gas in the fifty-one Scottish sea-lights, except Ailsa Craig, which has oil-gas. It should be added that the compressed mineral-oil gas of Messrs. Pintsch, and the petroleum spirit of Herr Lindberg, for the automatic lighting of buoys, have been, since 1878 , tried in this country with great success.

The third illuminant, electricity, has been known in England for about thirty-five years. As generated in the magneto-machines of Prof. Holmes between I853 and 1862 , and as tried experimentally in the lighthouses of Dungeness and South Foreland, it was very small in dimension and very uncertain in character. Several forms of the light were suggested during this period, such as the voltaic arc of Watson and the mercurial electric lamp of Way. With the more effective alternating current machines, and with the larger carbons, of later years, the arc grew in power and dimension. At the present time carboris of from 25 to 40 millimetres are available, with an intensity in the focus of a light of ten times that of the most powerful gas or oil burner. The arc is thus become a most valuable resource, not merely for its unsurpassable power, but also for its focal adaptability to the usual dioptric apparatus, and to special optical combinations dictated by nautical circumstances. It is most flexible in its application. It radiates no harmful heat
It has the high merit of not exacting any abnormal dimensions of apparatus, lantern, or tower. Lastly, being the most powerful in all its gradations relatively to other illuminants, it is the cheapest of all lights if the cost of establishment and maintenance be computed in terms of the units of the beam transmitted, which is the only strictly logical and practical way of treating it. For these reasons it has been chosen in France as the best illuminant for a large number of coast-lights, and it is making rapid way in Europe and America. It may therefore be safely asserted that the electric light, when it shall have been freed from its last disabilities, and shall have attained its utmost development, will, in the not distant future, be the prevailing illuminant of our own lighthouses and of the other chief lighthouses of the world.

In illustration of the power of the electric arc with suitable optical treatment, I may mention that the direct beams of the Tino light, near Spezia, were observed on April 20, 1885, by Prof. Noceti, from the hill S. Giorgio, behind Savona, at an elevation of 2733 feet, and a distance of 73 statute miles, the atmosphere being clear and under moonlight. The beams of the arc were notably brighter than those of the lanterna at Genoa, at one-third of the distance. Frequent observations are reported of the Macquarie light in New South Wales, at ranges of 60 , 65 , and 70 nautical miles, by means of reflections on the sky while the light itself is below the horizon.

The relative merits of gas, oil, and electricity, were established in the prolonged official experiments at the South Foreland in $1884-85$. It has been proved that there is no appreciable qualitative difference between mineral oil and coal-gas as light-giving agents ; and that such differences as appeared were rather quantitative, arising from the number and dimensions of the burners, and the modes of their collocation or superposition. It has been proved also that the electric arc (in addition to its superiority in clear weather, which was never in question) has an absolute superiority in thick weather to both gas and oil- "the greatest penetrative power in fog." Much public controversy has been excited by the Report in which conclusions like these are embodied. The fairness and impartiality of persons concerned in the investigation have even been impugned, and objection has been taken to the manner in which the electric light was presented to the observers, and to the refusal of the Trinity House to accept certain maximum arrangements called "double-triform" and "double quadriform." But to anyone reading the Report of the Trinity House (1885) with no bias toward a particular interest or a pre-conceived theory, it must appear that the inquiry was as exhaustive as it was prolonged, and that it is impossible that such names as those connected with it-names eminent in science, in engineering, and in the nautical and official world-should be associated with any other desire than the desire to shed light on a vexed technical question, and to achieve honourably and thoroughly a great public work. With regard to the exclusion of maximum combinations from the Foreland programme, it was obviously sufficient to compare gas and oil in their respective primary burners, multiplied or combined in such a way as, while insuring equal terms or nearly so, to reproduce the actual or allowable conditions of a lighthouse ; and nothing would seem to be gained by augmenting the rival elements pari gradu to ampler and ampler bulk regardless of all else. The inter-relation of the numbers one, two, three, is not affected, or very slightly so, by raising them to two, four, six, or to four, eight, twelve. And although the highest power of the initial flame or the emerging beam were reached according to the opinion of the moment, the next day might suggest a still higher power, until it became clear that we might as well revert to the old beacon-fire on the headland, for indeed with unlimited tar-barrels or profuse pine-logs a light could be kindled exceeding everything 
yet achieved by gas, oil, or electricity, and visible not only on the horizon, but across half the midnight sky.

Phonic signals as auxiliary to luminous signals have engaged the attention of our lighthouse authorities from dates previous to 1837 , and almost continuously from 1848 to 1875 . The early instruments were the bell, the gun, and the gong, with sometimes an explosive such as a rocket. Between 1848 and $\mathrm{I} 850, \mathrm{Mr}$. G. Wells produced his patent "fog screamer" (by atmospheric pressure), which, however, did not meet the approval of the Trinity House, who, in 1853 , considered that a goodsized bell struck sharply by machinery surpassed any mode yet tried. During the next ten years experiments on fog-signals were carried on in France, and in 1864 there was an important investigation by the Government of the United States. In 1872 a Committee of the Trinity House visited that country and Canada, and tested the merits of the new sound instruments in use, chiefly the Daboll horn actuated by air, and the siren actuated by steam. The Canadian and American steam-whistles and the New York siren, together with air-whistles, airtrumpets, and some guns, were next employed in the most complete scientific and practical inquiry ever held into the laws that regulate the passage of sound through the atmosphere, and into the mechanical agents most suitable to be adopted. The experiments were conducted by the Trinity House at the South Foreland in 1873-74, under the superintendence of Dr. Tyndall, who was able to demonstrate that fog or heavy rain is permeable by sound to a degree never before understood, and that optical transparency might be combined, even as cause and effect, with acoustical opacity or turbidity, and vice versâ. These results attracted much attention, and although Prof. Tyndall's inductions as to homogeneity or nonhomogeneity of the atmosphere have been to some extent questioned, the large body of facts on which they rest has been still further enlarged and confirmed. It follows that a fog dense enough to quench all light may permit sound to be transmitted with unimpaired distinctness and where the sound, either by alternations of pitch or of interval, is made a substitute for the characteristics of a light-signal, a very valuable secondary set of signals is realized. Of the instruments tried at the South Foreland the siren was found to be the most effective in almost all circumstances. This instrument was the work of Mr. Brown, of New York, to whom a simple and powerful form of caloric engine is also due. It consists of a trumpet about 17 feet long, increasing from 5 to 27 inches in diameter, having two disks in it, one fixed and one rotating, with radial slits in them. The rotation is from 2000 to 2500 times in a minute, steam at from 70 to 80 lbs. pressure being supplied. A note of varying pitch and intensity, audible at distances from 3 to ro miles is thus generated. The siren in another form was improved by Dove and by Helmholtz, and previously by Cagniard de la Tour, who gave it this name, presumably on the lucus a non lucendo principle. It is now employed at many first-class land lighthouses where space exists for the needful steam or caloric motor. Truly for the help not the harm of the mariner, in the words of the poet, "Siren assuetos effudit in cequore cantus." It is possible that the recent disaster off Dieppe might have been averted if the Victoria, moving doubtfully through the fog, could have heard the steam-trumpet on Cap d'Ailly, which seems to have been disabled at the critical time. Both the range of the siren and the facilities for working it have of late been enhanced by the methods of $\mathrm{Mr}$. Charles Ingrey, who, by employing air compressed by engines of 40 horse-power, the airpressure being 80 lbs. per square inch, has, in the case of the Ailsa Craig establishment, produced from two sirens a sound audible, it is said, at a distance of 20 miles in calm weather. One of these instruments gives single blasts of 5 seconds duration, the other a high, low, and high note in series, each of 2 seconds, with intervals of
2 seconds between them, followed by $\mathbf{I} 70$ seconds of silence. This is the phonic analogue of a single-flashing and of a group-flashing light respectively. The compressed air is conveyed from a considerable distance to the siren-house, and Mr. Ingrey is confident that he could work the instrument from an engine placed ro miles away. After the South Foreland experiments of $\mathbf{I} 874$ the Trinity House proceeded to improve the gun as a sound-signalling agent. It now ranks as second to the siren alone. Gun-cotton is proved to be a more effective charge than powder, and it has been supplied with the gun to a few lightships; but the siren is for principal stations, and the gong, or bell, or an explosive mixture, for others.

The details so far given, though necessarily incomplete, illustrate the notable progress in lighthouse design and construction attained in this country since the accession of our Queen, and not less do they show the increasing number of the lights established on our shores. Along with France and the United States-and due honour must be accorded to the eminent men representing them -Great Britain has proceeded steadily in the path of investigation and experiment. And here the labours of the celebrated Royal Commission of $1859-60$ on lights, buoys, and beacons should not be overlooked. This Commission collected from all maritime countries and from the leading authorities in official life, in engineering and nautical science, in mathematics and physics, a vast body of evidence which to the careful student will not prove the rudis indigestaque moles it at first sight appears. Some of the recommendations of the Commission have been fully carried into effect during the last quarter of a century, e.g. the proper adjustment of optical agents to the flame and to the sea horizon, the development of lamps and burners, the provision of reflectors, testing of foci, \&c. The conclusions also of the Commissioners on the complicated and anomalous system of lighthouse government formulated by the Merchant Shipping Act of 1854 have never been impugned; and the expediency of a central Lighthouse Board as suggested by them, and as indeed had been suggested by the Parliamentary Committee of 1834 , has become more and more evident down to the present day.

But while Great Britain has, in common with France and the United States, pursued this path of inquiry and reform, she has distanced these countries altogether in the results of research and the realisation of improvement. The splendid gift of the dioptric system was made to the world by the genius of Fresnel, yet little has been added to it by his countrymen. The most solid and important additions and applications are the work of Scottish and English engineers, whether in the optics or the mechanics of lighthouses, whether in oil, gas, or electricity. And the gift of Fresnel has thus been returned enhanced threefold to France and to the world. How it has been received is apparent by this one indication: the yearly statistics of our Admiralty comprise forty lighthouse notices issued to mariners in $I \delta 62$, and $31 \mathrm{I}$ issued in I 886 , the subjects of these notices being mainly new lights, and the new lights being mainly on the most modern lenticular system.

NOTE.--Since the above was written the small circle of men associated with lighthouse illumination has been broken by the death of its most distinguished member, Thomas Stevenson, who, during the whole of the half century under review, did more than any other to multiply for engineers the resources of his science, and to diminish for all the world the manifold perils of the sea.

The extraordinary power of the electric light has been referred to in connexion with the apparatus of Isola del Tino. In a recent communication to the Standard from "C. P. S." from Via Reggio, further testimony is given to this power in clear weather, but a far more important and 
controversial point is conclusively dealt with. The writer says :- "Again, though dimmed by heavy rain and thick fog, as it has been during the last few nights, the triple flash is always clear and unmistakable, and then produces, through the quasi-opaque atmosphere, and at a distance of thirty miles, the effect of the blurred disk of the moon on a small scale. This remarkable penetration power of the Tino light is conclusive proof, not only of how admirably it is designed and suited to its essential purpose as a guiding light under the peculiar atmospheric conditions of the Mediterranean, but also how hazardous it would be to dip-viz. to divert such a light, as has been suggested by some-from the horizon to the nearer sea in foggy weather, forsooth according to the bene placito of the man in charge, on the presumption that in such weather the luminous rays could not reach the horizon, and would therefore be wasted. This presumption is wholly fallacious in the Mediterranean, for in the Bay of Spezia, owing to its proximity to the Apennines, the rainfall is much greater than in other parts of the Tyrrhenean Sea, and banks of land fog can often be seen hanging over the bay and Tino, when the horizon as far as Leghorn, Gorgona, and even Corsica, is perfectly clear."

$$
\text { June I } 887 \text {. }
$$

J. KENWARD.

\section{REPORT OF THE BOARD OF TRADE ON WEIGHTS AND MEASURES.}

NE of the many official Reports which are laid annually before Parliament, but which unfortunately are not so carefully read by the general public as they might be, is a Report by the Board of Trade on their proceedings and business under the Weights and Measures Act of 1878. In Report No. 9, Sess. II., 1886, there is something of scientific interest to which we would invite the attention of our readers.

The only two units from which all Imperial measures and weights are derived are, as is well known, the yard and the pound, and material standards of these two units are deposited with the Board of Trade. The Act provides that an accurate copy of each of these standards is to be made, and an account of the verification of a new copy of the yard measure is given in the present Report. The results of the comparisons of the new yard, P.C. VI., with the Imperial standard yard No. I, show that it differs little from the original standard :-

$$
\text { P.C. VI. }=\text { No. } \mathrm{I}-0^{\circ} 0000034 \text { inch. } t=62^{\circ} \mathrm{F} \text {. }
$$

There are no two primary standards between which our present scientific methods cannot measure some difference, but the above two standards would appear to be as nearly alike as it is possible to make them.

In determining the rate of expansion by heat of the new standard yard (which is a bronze bar 36 inches long), it was found that with a rising temperature, the new bar expanded 0.000356 inch for $1^{\circ} \mathrm{F}$., but with a falling temperature it contracted at a lesser rate, $0^{\circ} 000343$ inch for $I^{\circ} F$. It is not stated whether this curious difference in the rate of expansion, as determined when the temperature is alternately rising and falling, is owing to the march of the mercurial thermometers or to other causes. Some doubt has arisen as to the rate of expansion of the metal (bronze) of which the Imperial standard was made. The thermometric expansions stated in the Report of the Astronomer-Royal on the construction of the Imperial standard (Phil. Trans. Roy. Soc., part iii., 1857, p. 6I) do not agree with those stated by Colonel Clarke and Sir Henry James in their Report on the comparisons of standards of length (1886). The actual rate of expansion of the Imperial yard was, in fact, not determined by the Standards Committee in 1857 , but was assumed to be the same as that of other similar bars of the same metal The more recent experience, however, is that no two bronze bars expand by heat at precisely the same rate, although they may be of the same dimensions, form, and material. The co-efficient of expansion of an alloy is slightly affected by differences in the age of the alloy, by its being subjected to extreme variations of heat and cold, and by peculiarities in molecular condition.

With reference to the metric system, we are glad to see that during 1886 standards of metric weight and measure were verified for certain authorities for use in scientific research or otherwise. It would, however, appear that in Japan, in the competition for commercial acceptance, the British system is at present outstripping the metric system.

The legal equivalent of the metre is 39.37079 inches, but, as some doubt has been expressed as to the scientific accuracy of this equivalent, Prof. W. A. Rogers, of Colby University, has undertaken to construct for the Standards Department a subdivided standard yard and metre, on which the precise length of the two standards shall be marked off, so that an exact inter-comparison of the two standards may, as far as practicable, hereafter be made at London and at the Bureau International des Poids et Mesures, at Paris.

In this Report we have for the first time complete and trustworthy information as to the standard weights and measures in use in China and Japan, Her Majesty's ministers at Pekin and Tokio having obtained the information from the native Governments and through the different local consuls.

During the year I 886 the Standards Department was specially engaged in the re-verification of the accuracy of its own standards, and in the issue to local authorities of some suggestions with reference to the duties of inspectors of weights and measures. Amongst the re-verifications particularly referred to we notice a memorandum on the re-verification of the gasmeasuring standards, a memorandum which shows the several conditions necessary for the accurate measurement of gas used for lighting purposes. The accuracy of the unit of volume, the cubic foot, is made to depend on the Imperial standard pound, and not on linear measurement. Experience has hitherto shown that the determination of the weight of a cubic foot of distilled water may best be made by means of a round vessel which holds a quantity of water equal to $62.32 \mathrm{I} \mathrm{lb}$. avoirdupois at $62^{\circ} \mathrm{F}$., rather than by a vessel of rectangular shape, which might be made to measure one foot in each of its dimensions. In this memorandum reference also is made to a slight difference in the methods of determining the zero, or freezing-points, of thermometers. It is, for instance, uncertain how long a thermometer should remain in melting ice or snow before its precise freezingpoint is noted. At the Bureau of Weights and Measures at Paris, for instance, the thermometer is only left in the pounded ice just long enough for it to reach the maximum of depression. With thermometers made of hard glass it is stated to be desirable not to hurry the observationsthe thermometers remaining long enough to allow the use of a micrometer, and several observations to be taken; but with other kinds of glass it is found to be desirable to be as quick as possible. This practice is also stated to be adopted at the Standards Offices at Berlin and Washington. On the other hand, at Kew the freezing-point of a thermometer is not observed until the instrument has been completely buried, both bulb and stem, up to $32^{\circ} \mathrm{F}$., or $0^{\circ} \mathrm{C}$., in well-pounded block ice for a period of not less than a quarter of an hour, care being always taken in cold weather to insure the whole of the ice being in a melting condition during the experiment by pouring a small quantity of tepid water over it from time to time.

Unlike the determinations of the rate of expansion of gas, there has not been made any determination of the rate of expansion of water which in exact experiments 